\title{
Revision of the Dependency Dimension of the Dimensional Clinical Personality Inventory ${ }^{1}$
}

\author{
Lucas de Francisco Carvalho ${ }^{2}$ \\ Universidade São Francisco, \\ Itatiba-SP, Brazil
}

\author{
Giselle Pianowski \\ Universidade São Francisco, \\ Itatiba-SP, Brazil
}

\begin{abstract}
The assessment of personality in pathologic levels is a field that requires investment. This study aimed to review the Dependency Dimension of the Dimensional Clinical Personality Inventory (IDCP). The study was conducted through the development of new items based on the literature, and by investigating the psychometric properties in a sample of 199 participants, aged between 18 and 54 years $(M=26.37, S D=8.13), 71.4 \%$ female, who responded to the IDCP, the NEO-PI-R, and the PID-5. The first step resulted in 57 items that were tested psychometrically. Then, the dimension remained with 18 items, with internal consistency of .89 , and three factors: Self-devaluation, Avoidance of abandonment, and Insecurity, with internal consistency between .79 and .91. The expected correlations coefficients were found between the Dependency dimension and the correlated dimensions and facets of the NEO-PI-R and PID-5. The results evidence the adequacy of the revised dimension.
\end{abstract}

Keywords: personality traits, psychometrics, psychological testing, personality disorders

\section{Revisão da Dimensão Dependência do Inventário Dimensional Clínico da Personalidade}

\begin{abstract}
Resumo: A avaliação da personalidade em níveis patológicos é um campo que demanda investimentos. Esse estudo teve como objetivo a revisão da dimensão Dependência do Inventário Dimensional Clínico da Personalidade(IDCP). Este trabalho foi realizado por meio da elaboração de novos itens com base na literatura e pela investigação das propriedades psicométricas em uma amostra de 199 participantes, com idades entre 18 e 54 anos $(M=26,37$; $D P=8,13)$, sendo 71,4\% mulheres, que responderam ao IDCP, ao NEO-PI-R e ao PID-5. A primeira etapa resultou em 57 itens que foram testados psicometricamente. Na segunda, a dimensão foi finalizada com 18 itens, com consistência interna de 0,89 e três fatores, sendo Autodesvalorização, Evitação do abandono e Insegurança, com coeficientes de consistência interna entre 0,79 e 0,91. Foram encontradas correlações esperadas entre a dimensão dependência e dimensões correlatas do NEO-PI-R e do PID-5. Os resultados evidenciam adequação da dimensão revisada.
\end{abstract}

Palavras-chave: traços de personalidade, psicometria, testes psicológicos, distúrbios da personalidade

\section{Revisión de la Dimensión Dependencia del Inventario Dimensional Clínico de la Personalidad}

\begin{abstract}
Resumen: La evaluación de la personalidad en niveles patológicos es un campo que requiere inversiones. Este estudio tuvo como objetivo examinar la dimensión Dependencia del Inventario Dimensional Clínico de la Personalidad (IDCP). Se llevó a cabo mediante el desarrollo de nuevos ítems basados en la literatura, y mediante la investigación de las propiedades psicométricas en una muestra de 199 participantes, entre 18 y 54 años $(M=26.37, D E=8,13)$, con 71,4\% de mujeres, que respondieron al IDCP, al NEO-PI-R y al PID-5. El primer paso se tradujo en 57 ítems. En el segundo, la escala se completó con 18 ítems, consistencia interna de .89, en tres factores, Auto-devaluación, Evitación del abandono y Inseguridad, con coeficientes de consistencia interna entre .79 y .91. Fueron encontrados correlaciones esperadas entre la dimensión Dependencia y dimensiones correlacionadas del NEO-PI-R y del PID-5. Los resultados muestran la adecuación de la dimensión revisada.
\end{abstract}

Palabras clave: rasgos de personalidad, psicometría, tests psicológicos, trastornos de la personalidad

The literature in recent decades has been highlighting deficiencies in categorical models for the diagnosis and assessment of personality disorders (Skodol et al., 2011; Zimmerman, 2012). There is a great initiative by researchers for the development of self-report instruments that presuppose the dimensional model for the evaluation of

\footnotetext{
${ }^{1}$ Support: São Paulo Research Foundation - FAPESP (Protocol no. 2012/12794-9).

2 Correspondence address:

Lucas de Francisco Carvalho. Programa de Pós-graduação em Psicologia da Universidade São Francisco. Rua Alexandre Rodrigues Barbosa, 45. CEP 13251-040. Itatiba-SP, Brazil. E-mail: lucas@labape.com.br
}

the pathological characteristics of personality. In Brazil, an example is the Dimensional Clinical Personality Inventory - IDCP (Carvalho \& Primi, 2011), based on the diagnostic criteria for personality disorders (American Psychiatric Association [APA], 2003) and on the clinical perspective of the area (Millon, Millon, Meagher, Grossman, \& Ramnath, 2004). However, considering the most recent research in the area, primarily section 3 of the fifth edition of the Diagnostic and Statistical Manual of Mental Disorders - DSM-5 (APA, 2013), which focuses on the assessment of personality disorders in a hybrid approach, that is, considering categorical and dimensional elements, the continuous improvement of the instrument's dimensions are necessary. The present study 
is inserted within this context, with specific focus on revising the Dependency dimension of the IDCP, which assesses primarily characteristics of the dependent disorder.

Dependent personality disorder includes features such as submissiveness, anxiety, and separation insecurity, which bring marked disorders for individuals in their life experiences (APA, 2003, 2013; Clark, 1990; Gore, Presnall, Miller, Lynam, \& Widiger, 2012; Millon et al., 2004; Shedler \& Westen, 2004). According to the DSM-5, this disorder comprises pervasive and excessive manifestations of subordination to others, excessive attachment, and fear of separation. The eight diagnostic criteria focused on characteristics such as constant need of support in decisionmaking and responsibilities, avoidance of disagreements or demonstrations of opposition, reduced autonomy and/ or initiative, and intense concern with loneliness or abandonment (APA, 2013), corroborated with much of the literature that has addressed this disorder (Clark, 1990; Gore et al., 2012; Millon et al., 2004; Shedler \& Westen, 2004). In addition, other dimensions that are particularly relevant for this diagnostic scenario are relational insecurity and emotional dependency (Livesley, Schroeder, \& Jackson, 1990; Morgan \& Clark, 2010; Pincus \& Gurtman, 1995), anxiety, depressiveness, vulnerability, compliance, modesty, and low assertiveness (Samuel \& Widiger, 2004). Likewise, Skodol et al. (2011), analyzing the various latent facets to personality disorders, points three that are directly related to the dependent personality disorder, namely: submissiveness, anxiety, and separation insecurity.

Then, based on the lack of measures to assess pathological characteristics of personality in Brazil (Carvalho, Bartholomeu, \& Silva, 2010), the IDCP was developed by Carvalho and Primi, in 2011. (Carvalho \& Primi, 2011). This self-report instrument has 163 items arranged in 12 dimensions: Dependency (difficulty in making decisions without help), aggressiveness (tendency to present aggressive behavior), Mood instability (oscillation in mood and low resilience), Eccentricity (unusual, atypical behavior and beliefs), Attention seeking (looking to be the center of attention), Distrust (inability to trust others), Grandiosity (beliefs about being superior and deserving special treatment), Isolation (tendency to be alone), Criticism Avoidance (inability to feel comfortable in social situations), self-sacrifice (tendency to accept personal losses in favor of others), Conscientiousness (need for organization and perfectionism), and Impulsiveness (reckless behavior), and it was based on the pathological personality characteristics presented by Theodore Millon (Millon \& Davis, 1996; Millon et al., 2004) and on the diagnostic criteria of axis II of the DSM-IV-TR (APA, 2003). Carvalho (2011), Carvalho and Primi (in press) and Carvalho, Primi and Stone (2014) provide analyses showing an adequate reliability coefficient for the IDCP dimensions, as well as favorable evidence of validity based on the internal structure (exploratory and confirmatory factor analysis and, and Rasch modeling) based on external variables (psychiatric diagnosis and psychological tests).

Besides, revision studies have been developed with the IDCP, in an effort to expand its evaluative coverage through new items, based on sources that were not used in its original design, and to strengthen the psychometric quality of the inventory in its specific dimensions. One example is the study by Carvalho, Souza, and Primi (2014), with the proposed revision of the Conscientiousness dimension, and the study by Carvalho, Sette, Capitão, and Primi (2014), directed to the review of the Attention Seeking dimension.

Accordingly, this study focused on the Dependency dimension of the IDCP. This dimension is characterized by personal beliefs of disability, guided by difficulty in self-confidence at decision-making and strong dependency on others. We highlight that high scores on this dimension suggest difficulties and losses to the individual, related to the dependent functioning; low scores in the IDCP dimensions suggest only that the person reports not presenting a particular functioning (Carvalho \& Primi, in press). In studies aiming at finding evidence of validity, the dimension was found to be related mainly to the dependent personality disorder (Carvalho \& Primi, in press). In addition, a study by Abela (2013), with 21 patients diagnosed with dependent personality disorder, showed significant increase in the dimensions Dependency, Avoidance of Criticism, and Self-Sacrifice of the IDCP, in which high scores on the Avoidance Reviews must be weighted by high prevalence of comorbidity of these patients with avoidant personality disorder $(N=14)$. Importantly, the IDCP was developed with clinical focus for evaluation of pathological personality characteristics; however, the data demonstrate the appropriateness of the use of this test in the general population (Carvalho \& Primi, in press).

The present study aimed to review the Dependency dimension of the IDCP. Whereas we expected to find specific factors in the revised dimension, which did not occur with the original version of the instrument, we also sought to investigate whether the identified factors would be justified for the future establishment of profiles. Two conditions are necessary for the establishment of profiles in the Dimension: finding more than one single general factor composing the dimension, and moderate magnitudes, but not very close to 1 , of correlation between the factors.

\section{Method}

In this research, the method was divided in two stages: Step 1, directed to the development of new items for the Dependency dimension of the Dimensional Clinical Personality (IDCP), by means of analysis of the literature, and Step 2, in order to verify the psychometric properties of the revised version of the Dependency dimension in the IDCP. 


\section{Stage 1}

For the revision of the Dependency dimension of the IDCP, we consulted the literature that is considered prominent on the pathological manifestations of personality. Thus, the following references were analyzed: DSM-5 (APA, 2013) facets of the Personality Inventory for DSM-5 - PID-5 (Krueger, Dellinger, Markon, Watson, \& Skodol, 2012), the dimensions of the Shedler-Westen Assessment Procedure - SWAP-200 (Shedler, \& Westen, 2004) and the Clark model (1990) that supports the Schedule for Nonadaptive Personality (SNAP). It is emphasized that with regard to the DSM-5, section 3 was accessed, which refers to the hybrid model proposed by the task force of personality disorders which comprises the categorical and dimensional perspective (for details on the hybrid model, for example Skodol et al., 2011).

Based on the proposed literature, we sought to list constructs and specific characteristics of personality related to Dependency, which was mainly achieved by selecting content that was typically related to the dependent functioning (APA, 2013; Millon et al., 2004). The content (i.e., items and definitions of the factors of the instruments; and definitions of constructs) was prepared in an electronic spreadsheet, in sentences in the original language, English. After careful selection of the sentences, they were translated by two independent judges, authors of this study, and the final and consensual translation was transposed, which was used as a basis for the development of new items. We opted for the translation by the authors themselves, considering that (a) the translation did not aim to translate and culturally adapt the instruments and/or accessed literature, but rather to use the constructs and selected sentences in Portuguese, language of the instrument that is being reviewed; (b) the authors involved with this work and with the translation, by having researched deeply on the literature, should incur in less biases of translation, especially for words typically used in the area; and (c), one of the judges has extensive knowledge in relation to the IDCP and works in the area of personality disorders for over five years, and the other judge is a doctoral student, with a Masters degree in psychology with emphasis on psychological evaluation, who works specifically with the assessment of healthy and pathological personality.

The creation of the items was conducted independently by two researchers. Then, the judges (the study authors) selected the items that were considered the most suitable regarding the representation of the pathological manifestations of the dependency construct and the clarity and non-ambiguity of the writing. Next, for the establishment of the final set of items for administration, researchers reached a consensus, and as a final step in the procedure, the items that presented content already significantly represented in the original dimension of the IDCP were excluded.

\section{Stage 2}

\section{Participants}

Research participants were 199 subjects, including students of a private university in the countryside of the state of São Paulo as well as students' acquaintances. The age ranged from 18 to 54 years $(M=26.37, S D=8.13)$ with 142 females $(71.4 \%)$, mostly with incomplete higher education (51.8\%), followed by complete high school (20.6\%), accessed by convenience. As for the history of psychiatric treatment, $10 \%$ of subjects responded that they had already been to or are undergoing psychiatric treatment and $4.5 \%$ of the participants have used psychotropic medication. As for psychological counseling, $31.2 \%$ of participants reported having undergone psychotherapeutic monitoring and $11.6 \%$ are still on psychotherapy. It is noteworthy that information on the history of psychiatric diagnosis of the participants was not collected.

\section{Instruments}

Dimensional Clinical Personality Inventory - IDCP (Carvalho \& Primi, in press). In addition to the information already presented about the IDCP, we emphasize that its items are arranged in a 4-point Likert-like scale, where 1 is it has nothing to do with me and 4, it has everything to do with me, with an average administration time of 25 minutes. Regarding the psychometric properties of the IDCP dimensions, Carvalho and Primi (in press) and Carvalho, Primi et al. (2014) report that exploratory and confirmatory factor analyzes were performed, with good reliability by means of Cronbach's alpha for eleven dimensions of the instrument (excluding Conscientiousness, whose Cronbach's $\alpha$ was equal to .69), considering a cut-off point of .70 (Nunnally, 1978). There were also consistent relationships between the IDCP and the NEO-PI-R and diagnoses of personality disorders were observed (Carvalho, 2011).

Revised NEO Personality Inventory - NEO-PI-R Brazilian version (Costa Junior \& McCrae, 2009). It consists of a self-report inventory, composed of 240 items, with objective assessment of adult personality in five dimensions: Neuroticism, Extraversion, Openness, Agreeableness, and Conscientiousness. The instrument should be answered on a Likert-like scale of 5 points, ranging from strongly disagree (1) to strongly agree (5). The application time for this instrument is about 25 minutes. The manual of the Brazilian version of the instrument presents several studies showing evidence of validity and good reliability indices (Costa Junior \& McCrae, 2009). For this study, the Neuroticism and Agreeableness dimensions were analyzed, which present the facets most typically related to the dependent personality disorder (Samuel \& Widiger, 2004). The internal consistency reliability coefficients (Cronbach's alpha) of the factors of the NEO-PI-R were equal to .90 and .80 , respectively.

Personality Inventory for DSM 5 - PID-5 - Brazilian version (Krueger et al., 2012). This is a self-report inventory 
for assessing pathological characteristics of personality, consisting of 220 items that generate 25 facets (grouped into five dimensions), which should be completed in a Likert-like scale of 4 points (being zero very false or often false and three very true or often true). The PID-5 was developed to measure the criterion B of the proposal for the assessment of personality disorders for the DSM-5. There were no national studies verifying the psychometric properties of the Brazilian version of the instrument, but Krueger et al. (2012) presented data indicating the adequacy of the original test. For this study, the following facets were analyzed: Depressiveness $(\alpha=.90)$, Separation Insecurity $(\alpha=.81)$, Submissiveness $(\alpha=.80)$, and Anxiety $(\alpha=.80)$.

\section{Procedure}

Data collection. The administration was performed, mostly collectively, during about 40 minutes in an only session per class in university classrooms. According to the demand and access, some administrations occurred individually in private establishments, through personal contact. After the explanation of the research objectives, the instruments were administered, seeking to alternate the sequence of presentation thereof.

Data analysis. The data were entered into an electronic spreadsheet and then we proceeded to the statistical analysis. First, the maximum number of factors to be checked in the exploratory factor analysis was calculated based on the parallel analysis (Hayton, Allen, \& Scarpello, 2004; Watkins, 2006). Placement analysis was performed using R software version 2.15.3, since it allows the use of parallel analysis to polychoric variables. From this, a database was generated for the software MPlus version 6.12 in order to carry out the exploratory factor analysis to polychoric variables, as well as obtaining confirmatory indices indicating the adequacy of the structure found with basis on this sample. We used Geomin oblique rotation and Robust Maximum Likelihood (MLR) extraction method, considered a robust method suitable for polychoric variables.

Finally, correlation analyses were performed between the factors found for the Dependency dimension, the two dimensions of the NEO-PI-R, and the four facets of PID-5.

\section{Ethical Considerations}

The study was approved by the Research Ethics Committee of the Universidade São Francisco (CAAE. 21992113.1.0000.5514). Participation was voluntary, by signature of the Informed Consent Form.

\section{Results}

The survey in the literature of the most relevant features for the Dependency dimension resulted in the listing of constructs such as Anxiety, Depressiveness, Separation Anxiety, Submissiveness, Dysphoria, Self-effacement,
Dependency, and Hypersensitivity (APA, 2013; Clark, 1990; Kruger et al., 2012; Shedler \& Westen, 2004). By Anxiety we mean the experience of intense tension and preoccupation; Depressiveness is related to self-devaluation characteristics and general dissatisfaction; Separation Anxiety refers to concern with loneliness and distancing from people; and Submissiveness presents attributes of exaggerated regard for the opinion and direction of others (APA, 2013; Kruger et al., 2012). Dysphoria presents features such as inferiority, displeasure, maladjustment, and meaninglessness (Shedler \& Westen, 2004). Self-effacement refers to characteristics of low self-esteem and self-devaluation. Dependency includes demonstrations focused on the need of others for directions and decisions and fear of abandonment and/or loneliness; and hypersensitivity is the difficulty in dealing with criticism for fear of rejection (Clark, 1990).

Based on this information, 188 initial items were developed. Independently, we selected the items regarded as most appropriate to the proposed content and that clearly represented a pathological manifestation of the dimension, which resulted in the pre-selection of 72 items. The final selection presented as an inclusion criterion items that had content that was not well represented yet in the 20 original items of the IDCP, which was conducted by consensus among researchers and resulted in the inclusion of 37 new items developed in this study.

The total set of 57 items was investigated regarding their psychometric properties. Therefore, we started from the parallel analysis for polychoric variables, in the search for determining the maximum number of factors for the Dependency dimension revised. We got up to four factors with expressive eigenvalues not evidenced by chance. We analyzed the adjustment indices generated for the three models and found that the model of three and four factors showed virtually no difference, which can be observed by AIC (19832.466 for three factors and 19717.487 for four factors) and BIC (20715.098 for three factors and 20769.133 for four factors) indices. Still, the four-factor model showed a slightly better adequacy, that is, the indices showed higher adjustment to the mathematical model. Both models were submitted to interpretative analysis according to the load of the items, which revealed that the four-factor model hardly showed items with significant loads (greater than .30) in its last factor. Based on this information and on the proximity of adjustment of the two solutions, we opted for the factorial solution composed of three factors. The adjustment indices obtained by the three-factor model were $X^{2} / d f=1.82$ (good); $R M S E A=.070$ (acceptable); $C F I=.753$ (unsatisfactory); and, $S M R=.057$ (good), based on Hooper, Coughlan, and Mullen (2008). The factor loadings, the number of items held by factor, and the internal consistency indices (Cronbach's alpha) are shown in Table 1. In addition, the items that remained in each of the factors are in bold.

It can be verified that the final version of the revised Dependency dimension was composed of 18 items, divided 
Carvalho, L. F., \& Pianowski, G. (2015). Review of the Dependency Dimension.

Table 1

Exploratory Factor Analysis and Internal Consistency Indices

\begin{tabular}{|c|c|c|c|}
\hline Item & Self-Devaluation & $\begin{array}{l}\text { Avoidance of } \\
\text { Abandonment }\end{array}$ & Insecurity \\
\hline 18 & .37 & .09 & .57 \\
\hline 21 & .28 & .18 & .66 \\
\hline 70 & .49 & .16 & .60 \\
\hline 178 & .43 & .55 & .44 \\
\hline 402 & .29 & .72 & .28 \\
\hline 403 & .31 & .73 & .32 \\
\hline 406 & .41 & .61 & .27 \\
\hline 407 & .29 & .63 & .17 \\
\hline 408 & .31 & .56 & .17 \\
\hline 416 & .78 & .28 & .34 \\
\hline 417 & .73 & .29 & .27 \\
\hline 418 & .80 & .34 & .46 \\
\hline 419 & .77 & .26 & .43 \\
\hline 420 & .78 & .36 & .33 \\
\hline 425 & .43 & .37 & .77 \\
\hline 426 & .51 & .46 & .67 \\
\hline 435 & .68 & .37 & .36 \\
\hline 436 & .59 & .20 & .32 \\
\hline N. items & 7 & 6 & 5 \\
\hline A & .91 & .81 & .79 \\
\hline
\end{tabular}

Note. For clarity, only items that were kept are shown in the tables. The items composing the factor in the final version are in bold.

into three factors, ranging from 5 to 7 items per factor. It is important to highlight that we sought to explicitly maintain a minimum number of items per factor, since the IDCP is composed of twelve dimensions and it would be impossible to use such an extensive and comprehensive instrument by professionals. Thus, we excluded from the factors some items with adequate factor loading.

Basically, four criteria were used for the exclusion of items: (a) the item affected or did not favor the internal consistency of the factor, (b) little interpretative consistency for maintenance of the item in the factor (i.e., the item content was not strongly related to the factor regarding the other items composing the factor), (c) significant loads in other factors (difference lower than 0.50 in intra-factor loads), and (d) content redundancy between items in the same factor. Regarding the internal consistency of the factors found, we verified that all had a coefficient higher than 0.70 , whereas the dimension index of 0.89 was obtained for the total set of 18 items. After defining the instrument's internal structure, the factors of the dimension and its total score were related and compared with dimensions and facets of other psychological instruments. Table 2 shows the results of the correlations between the factors and the total score of the new Dependency dimension with the two dimensions of the NEO-PI-R.

It is important to note that the magnitudes found for the correlations between the factors of the revised dimension
Table 2

Correlations Between the Total Score, Factors, and Dimensions of the NEO-PI-R

\begin{tabular}{lccccccc}
\hline & 1 & 2 & 3 & 4 & 5 & 6 & 7 \\
\hline $\begin{array}{l}\text { - Self- } \\
\text { Devaluation }\end{array}$ & 1 & & & & & & \\
$\begin{array}{l}\text { - Avoidance of } \\
\text { Abandonment }\end{array}$ & $.44^{* *}$ & 1 & & & & & \\
3 - Insecurity & $.50^{* *}$ & $.39^{* *}$ & 1 & & & & \\
4 - Revised & $.84^{* *}$ & $.78^{* *}$ & $.73^{* *}$ & 1 & & & \\
$\begin{array}{l}\text { Dependency } \\
5 \text { - Original }\end{array}$ & $.66^{* *}$ & $.54^{* *}$ & $.82^{* *}$ & $.83^{* *}$ & 1 & & \\
$\begin{array}{l}\text { Dependency } \\
6 \text { - Neuroticism }\end{array}$ & $.62^{* *}$ & $.44^{* *}$ & $.48^{* *}$ & $.66^{* *}$ & $.64^{* *}$ & 1 & \\
7 - Agreeableness & -.10 & -.10 & .01 & -.13 & -.08 & $-.22^{* *}$ & 1 \\
\hline
\end{tabular}

Note. 1 = Self-Devaluation; 2 = Avoidance of Abandonment; 3 = Insecurity; 4 = Revised Dependency; 5 = Original Dependency; $6=$ Neuroticism; 7 = Agreeableness.

${ }^{*} p \leq .05 .{ }^{* *} p \leq .01$.

ranged between .39 and .50 , and of the factors with the total score, between .73 and .84 . We also calculated the total score of the Dependency dimension only with the original items, which showed a significant decrease in magnitude with the factors of dimension in relation to the total score of the revised version of the dimension. In the same table there are also the magnitudes of correlation between the factors of the revised dimension and two dimensions of NEO-PI-R. Specifically with regard to relations with Neuroticism, we observed very close positive magnitudes between the total scores (original and revised) and greater magnitude with the self-devaluation factor. On the other hand, the magnitudes for Agreeableness were low, with a tendency for a negative relationship. Next, the magnitudes of correlation of the revised dimension and factors with the facets of Neuroticism, Agreeableness and also with the PID-5 are shown in Table 3.

We observed that the total score revised presented correlations with higher magnitudes with the Neuroticism facets of the NEO-PI-R (Anger/Hostility, Depression, Impulsivity, and Vulnerability) for most of the facets in relation to the original total score, but not for all (Anxiety and Embarrassment/Consciousness). With regard to the factors of the Dependency dimension, self-devaluation and Avoidance of Abandonment had higher magnitudes with Depression, and Insecurity with Vulnerability. As for Agreeableness, most relationships found were low. Still, the greatest magnitudes observed were with Trust (and the factors self-devaluation and Avoidance of Abandonment), besides relations with the total scores (the negative relationship with the revised score was notably more significant).

Further, with regard to the relationship with the PID-5, we observed that all correlations were statistically significant, most of them ranging from moderate to high. The total score revised showed greater correlation magnitudes for two of the three facets. In addition, self-devaluation related more, expressively with Depressiveness, Avoidance of Abandonment with Separation Insecurity, and Insecurity with Submissiveness. 
Table 3

Correlation Between Dependency and Facets of Neuroticism, Agreeableness, and PID-5

\begin{tabular}{|c|c|c|c|c|c|c|}
\hline & Facets & Self-Devaluation & $\begin{array}{l}\text { Avoidance of } \\
\text { Abandonment }\end{array}$ & Insecurity & $\begin{array}{c}\text { Revised } \\
\text { Dependency }\end{array}$ & $\begin{array}{c}\text { Original } \\
\text { Dependency }\end{array}$ \\
\hline \multirow[t]{6}{*}{ Neuroticism } & Anxiety & $.32^{* *}$ & $.26^{* *}$ & $.40^{* *}$ & $.42^{* *}$ & $.48^{* *}$ \\
\hline & Anger/Hostility & $.36^{* *}$ & $.33^{* *}$ & $.26^{* *}$ & $.42^{* *}$ & $.40^{* *}$ \\
\hline & Depression & $.70^{* *}$ & $.43^{* *}$ & $.34^{* *}$ & $.63^{* *}$ & $.54^{* *}$ \\
\hline & $\begin{array}{l}\text { Self-Consciousness/ } \\
\text { Embarrassment/ }\end{array}$ & $.50^{* *}$ & $.33^{* *}$ & $.46^{* *}$ & $.56^{* *}$ & $.57^{* *}$ \\
\hline & Impulsiveness & $.29^{* *}$ & $.20^{* *}$ & $.18^{*}$ & $.28^{* *}$ & $.27^{* *}$ \\
\hline & Vulnerability & $.49^{* *}$ & $.36^{* *}$ & $.49^{* *}$ & $.58^{* *}$ & $.57^{* *}$ \\
\hline \multirow[t]{6}{*}{ Agreeableness } & Trust & $-.30^{* *}$ & $-.23^{* *}$ & -.08 & $-.30^{* *}$ & $-.24^{* *}$ \\
\hline & Straightforwardness & .04 & -.04 & .04 & -.01 & -.02 \\
\hline & Altruism & -.08 & -.02 & 0 & -.07 & -.01 \\
\hline & Compliance & -.05 & .04 & .09 & 0 & .01 \\
\hline & Modesty & $.20^{* *}$ & .01 & .09 & .09 & .11 \\
\hline & Tender-Mindedness & -.14 & -.12 & -.10 & $-.16^{*}$ & -.14 \\
\hline \multirow[t]{4}{*}{ PID-5 } & Depressiveness & $.80^{* *}$ & $.35^{* *}$ & $.39^{* *}$ & $.68^{* *}$ & $.58^{* *}$ \\
\hline & Separation Insecurity & $.45^{* *}$ & $.74^{* *}$ & $.41^{* *}$ & $.68^{* *}$ & $.58^{* *}$ \\
\hline & Submissiveness & $.48^{* *}$ & $.42^{* *}$ & $.69^{* *}$ & $.62^{* *}$ & $.66^{* *}$ \\
\hline & Anxiety & $.60^{* *}$ & $.43^{* *}$ & $.35^{* *}$ & $.59^{* *}$ & $.51^{* *}$ \\
\hline
\end{tabular}

${ }^{*} p \leq .05 .{ }^{* *} p \leq .01$.

\section{Discussion}

The Dependency dimension of the IDCP originally includes the assessment of personal characteristics such as disability and strong need for support and guidance of others in decision-making (Carvalho \& Primi, in press). According to the study by Abela (2013), this dimension is correlated with the Dependent personality disorder, which includes features like Submissiveness, Anxiety, and Separation insecurity (APA, 2013). As a result of the first stage of this study, we obtained a new version for the dimension, aiming to get deeper into the characteristics related to this functioning: Anxiety, Depressiveness, Separation Anxiety, Submissiveness, Dysphoria, Self-effacement, Dependency, and hypersensitivity. The version revised and tested empirically ended with 57 items, in which the constructs Submissiveness and Self-devaluation, already represented in the original items, were reinforced, the manifestations related to Separation Anxiety were expanded, and items directed to hypersensitivity to criticism and guilt were included.

After psychometric analysis, the Dependency dimension ended with 18 items divided into three factors, named as selfdevaluation (7 items), Avoidance of Abandonment (6 items) and Insecurity (5 items), with adequate internal consistency coefficients (Embretson, 1996; Nunnally, 1978). In the selfdevaluation factor there are features of self-devaluation in favor of others, feelings of inability and guilt, exemplified by the item "I know I do a lot of things wrong, and I feel guilty about it." In Avoidance of Abandonment, the items show manifestations of separation anxiety, fear of loneliness and abandonment, as an example "I am afraid of being abandoned and having to get by on my own." In the Insecurity factor, there are attributes such as submissiveness, constant need for others in decision-making and directions, exemplified by the item "People can make me change my mind easily, even when I thought I was determined.” The factors found were consistent with the literature and suggest adequacy of the evaluation of Dependency on the IDCP.

We observed that the correlations between the factors of the Dependency dimension were from low to moderate, which suggests the possibility of discriminating individuals into profiles in the Dependency dimension, and which should be verified in further studies and may be of great value in the use of IDCP in the clinical setting. On the other hand, the high correlation values between factors and the total score of the dimension indicate the presence of a common latent construct between factors, in this case, dependency. Then, the new dimension was correlated with other instruments that assess constructs considered related, the NEO-PI-R and the PID-5.

Understanding that the NEO-PI-R does not present any dimension and/or aspect directly related to the dependent functioning, we chose to investigate correlations with dimensions that theoretically make sense, in the case, Neuroticism and Agreeableness. The Neuroticism factor was correlated with the new dimension, which was expected, as this dimension comprises characteristics such as anxiety and depressiveness, consistent with a pathological continuum and consistent with the literature related to Dependency. Regarding the correlations between the factors of the new dimension and the facets of Neuroticism, we identified that self-devaluation and Avoidance of abandonment, from the IDCP, were highly correlated with the depression facet, 
consistent with the tendency to negative affection, relevant to the literature regarding the presence of depressiveness characteristics on Dependency (Kruger et al., 2012; Samuel \& Widiger, 2004; Shedler \& Westen, 2004), and the Insecurity with Vulnerability, facet related to susceptibility to stress, which is also included in features like anxiety (Widiger \& Samuel, 2004; Skodol et al., 2011), hypersensitivity (Clark, 1990), or the relational or separation insecurity (Livesley et al., 1990; Morgan \& Clark, 2010;. Skodol et al., 2011).

With the Agreeableness factor of the NEO-PI-R, the correlations were low with the tendency to a negative direction, which, a priori, was not expected. One can attribute this result to possible qualitative distinctions between the Agreeableness dimension, focused on trust, compliance, and altruism, and the Dependency dimension, directed to insecurity, fear of abandonment, and submission. That is, it is possible that there is no dimensional continuum established between the characteristics of the dimension Dependency with Agreeableness. Still, we emphasize the correlation between the Trust facet, corresponding to the predisposition in believing that others are honest and well-meaning, and the factors self-devaluation and Avoidance of Abandonment of the IDCP. This relationship can be understood as personal devaluation in favor of overvaluation of the other (Clark, 1990; Kruger et al., 2012; Shedler \& Westen, 2004), directed to the avoidance of abandonment (Clark, 1990; Livesley et al., 1990; Morgan \& Clark, 2010; Skodol et al., 2011), present in the Dependency dimension.

Besides, the correlation of Dependency with the PID-5 facets revealed moderate to high magnitudes. The self-devaluation dimension (IDCP) correlated with Depressiveness and Anxiety (PID-5), suggesting that people who tend to devaluate their own value towards others also tend to express a negative and worried view of themselves, the world, and the future, which is conceptually relevant. The avoidance of abandonment showed a significant correlation with separation insecurity, which was expected, since this dimension of the IDCP and the PID-5 facet have very similar definitions (the latter referring to dealing with the fear of abandonment and loneliness). We also emphasize the correlation between Insecurity and Submissiveness, suggesting that people who tend to have difficulty making important decisions by themselves also tend to be submissive to others, which is conceptually coherent. The correlations evidenced allow identifying that the factors of the revised dimension evaluate relevant aspects of the dependent functioning, based on the facets of the PID-5.

We observed that the correlations of the Dependency dimension with the PID-5 facets were more significant than with the NEO-PI-R, which is more evident with the Agreeableness dimension. Thus, correlations between the PID-5 and the Agreeableness of the NEO-PI-R were also conducted in order to verify whether these also distanced from each other, which would reinforce the idea that the latter is more focused on evaluating healthy aspects of personality. The results showed that the correlations between the four facets of PID-5 and the six facets of Agreeableness of the NEO-PI-R showed low magnitudes, ranging from .03 to -.34 , only one above .30 (Trust/NEO-PI-R and Depressiveness/PID-5), one equal to -.30 (Trust/NEO-PI-R and Anxiety/PID-5), and two between .29 and .20 (Modesty/NEO-PI-R and Separation Insecurity /PID-5, and Trust/NEO-PI-R and Separation Insecurity /PID-5). We understand this data as an important sign that both the IDCP and the PID-5 tend to evaluate pathological aspects of personality, and that there must be a quantitative break to be taken into account between these levels of assessment and the level estimated by the Agreeableness dimension of the NEO-PI-R, which indicates the need for further research in this direction.

In addition, emphasizing the direction of the IDCP to pathological levels, we signal that the revised dimension is subtly more pathological than the original, which was identified in two stages. First, on the two aspects of the Agreeableness dimension of NEO-PI-R, correlated significantly with the total scores of the Dependency dimension in which the revised version showed greater negative magnitude than the original, suggesting a greater tendency of the revised dimension to pathological levels. And the total score of the revised dimension also features revised higher magnitudes of correlation with most of the PID-5 facets, these aimed to the evaluation of pathological aspects of personality related to the dependent functioning. An exception is the Submissiveness facet, which showed a higher correlation with the original dimension, which is explained by the fact the original dimension of the IDCP includes items almost entirely directed only to submissiveness characteristics. However, correlation data are fairly fragile for such claim and, therefore, we suggest that future studies use other procedures to monitor this aspect of the dimension, for example, analyzes based on Item Response Theory (IRT).

The results and discussions presented show that the main objective of this study was achieved, i.e., the development of a new set of items for the Dependency dimension of the IDCP with adequate psychometric properties. We identified evidence of validity based on the internal structure and in relation to external variables, as well as high reliability coefficients of the revised dimension. The results suggest that the dimension revised may be used clinically with people from the general population, and possibly with psychiatric patients, however, this last point should be further investigated. There is also evidence that it is possible to establish profiles from the factors found, which should be investigated in further research. Still, future studies should seek to relate the Dependency dimension revised with the other factors of NEO-PI-R and facets of the PID-5.

As limitations, we may cite the sample, the number of participants, and their characteristics, not including patients with personality disorders. Another limitation is the non-participation of external members in the translation, creation, and adaptation of the items created. It is suggested 
that future studies seek replicability of the structure found in several samples, emphasizing the relevance of clinical samples. It is also relevant that the reliability index is be checked based on the levels of the subjects in the latent construct, for instance, via precision location (Daniel, 1999). Furthermore, we identify the need for assessing the applicability of the IDCP Dependency dimension in clinical evaluation.

\section{References}

Abela, R. K. (2013). Evidências de validade para o Inventário Dimensional Clínico da Personalidade (IDCP) com base nos perfis de participantes com diagnóstico psiquiátrico (Unpublished master's thesis). Universidade Federal de São Paulo, São Paulo, SP.

American Psychiatric Association. (2003). DSM IV-TR: Diagnostic and statistical manual of mental disorders (4th ed. rev.). Washington, DC: American Psychiatry Association.

American Psychiatric Association. (2013). DSM-5: Diagnostic and statistical manual of mental disorders (5th ed.). Washington, DC: American Psychiatry Association.

Carvalho, L. F. (2011). Desenvolvimento e verificação das propriedades psicométricas do Inventário Dimensional Clínico da Personalidade (Unpublished doctoral dissertation). Universidade São Francisco, Itatiba, SP.

Carvalho, L. F., Bartholomeu, D., \& Silva M. C. R. (2010). Instrumentos para avaliação dos transtornos da personalidade no Brasil. Avaliação Psicológica, 9(2), 289-298.

Carvalho, L. F., \& Primi, R. (in press). Development and internal structure investigation of the Dimensional Clinical Personality Inventory. Psicologia: Reflexão e Crítica.

Carvalho, L. F., Primi, R., \& Stone, G. E. (2014). Psychometric properties of the Inventário Dimensional Clínico da Personalidade (IDCP) using the Rating Scale Model. Avances en Psicología Latinoamericana, 32(3), 433-446. doi:10.12804/apl32.03.2014.09

Carvalho, L. F., Sette, C. P., Capitão, C. G., \& Primi, R. (2014). Propriedades psicométricas da versão revisada da dimensão necessidade de atenção do Inventário Dimensional Clínico da Personalidade. Temas em Psicologia, 22(1), 147-160. doi:10.9788/TP2014.1-12

Carvalho, L. F., Souza, B. D. B., \& Primi, R. (2014). Psychometric properties of the revised conscientiousness dimension of Inventário Dimensional Clínico da Personalidade (IDCP). Trends in Psychiatry and Psychotherapy, 36(1), 23-31. doi:10.1590/2237-6089-2013-0024

Clark, L. A. (1990). Toward a consensual set of symptom clusters for assessment of personality disorder. In $\mathrm{J}$. N. Butcher \& C. D. Spielberger (Eds.), Advances in personality assessment (Vol. 8, pp. 243-266). Hillsdale, NJ: Lawrence Erlbaum.

Costa Junior, P. T., \& McCrae, R. R. (2009). NEO-PI-R: Inventário de Personalidade NEO Revisado: Manual. São Paulo, SP: Vetor.
Daniel, M. H. (1999). Behind the scenes: Using new measurement methods on DAS and KAIT. In S. E. Embretson \& S. L. Hershberger (Eds.), The new rules of measurement: What every psychologist and educator should know (pp. 37-63). Mahwah, NJ: Lawrence Erlbaum.

Embretson, S. E. (1996). The new rules of measurement. Psychological Assessment, 8(4), 341-349. doi:10.1037/1040-3590.8.4.341

Gore, W. L., Presnall, J. R., Miller, J. D., Lynam, D. R., \& Widiger, T. A. (2012). A five-factor measure of dependent personality traits. Journal of Personality Assessment, 94(5), 488-499. doi:10.1080/00223891.2012.670681

Hayton, J. C., Allen, D. G., \& Scarpello, V. (2004). Factor retention decisions in exploratory factor analysis: A tutorial on parallel analysis. Organizational Research Methods, 7(2), 191-205. doi:10.1177/1094428104263675

Hooper, D., Coughlan, J., \& Mullen, M. R. (2008). Structural equation modelling: Guidelines for determining model fit. Electronic Journal of Business Research Methods, 6(1), 53-60.

Krueger, R. F., Derringer, J., Markon, K. E., Watson, D., \& Skodol, A. E. (2012). Initial construction of a maladaptive personality trait model and inventory for DSM-5. Psychological Medicine, 42(9), 1879-1890. doi:10.1017/S0033291711002674

Livesley, W. J., Schroeder, M. L., \& Jackson, D. N. (1990). Dependent personality disorder and attachment problems. Journal of Personality Disorders, 4(2), 131-140. doi:10.1521/pedi.1990.4.2.131

Millon, T., \& Davis, R. D. (1996). Disorders of personality: DSM-IV and beyond (2nd ed.). New York, NY: John Wiley and Sons.

Millon, T., Millon, C. M., Meagher, S., Grossman, S., \& Ramnath, R. (2004). Personality disorders in modern life (2nd ed.). Hoboken, NJ: Wiley.

Morgan, T. A., \& Clark, L. A. (2010). Passive-submissive and active-emotional trait dependency: Evidence for a twofactor model. Journal of Personality, 78(4), 1325-1352. doi:10.1111/j.1467-6494.2010.00652.x

Nunnally, J. C. (1978). Psychometric theory. New York, NY: McGraw-Hill.

Pincus, A. L., \& Gurtman, M. B. (1995). The three faces of interpersonal dependency: Structural analyses of self-report dependency measures. Journal of Personality and Social Psychology, 69(4), 744-758. doi:10.1037/0022-3514.69.4.744

Samuel, D. B., \& Widiger, T.A. (2004). Clinicians' personality descriptions of prototypic personality disorders. Journal of Personality Disorders, 18(3), 286-308. doi:10.1521/pedi.18.3.286.35446

Shedler, J., \& Westen, D. (2004). Dimensions of personality pathology: An alternative to the five factor model. American Journal of Psychiatry, 161(10), 1743-1754. doi:10.1176/appi.ajp.161.10.1743 
Skodol, A. E., Clark, L. A., Bender, D. S., Krueger, R. F., Morey, L. C., Verheul, R., ... Oldham, J. M. (2011). Proposed changes in personality and personality disorder assessment and diagnosis for DSM-5 Part I: Description and rationale. Personality Disorders: Theory, Research, and Treatment, 2(1), 4-22. doi:10.1037/a0021891

Watkins, M. W. (2006). Determining parallel analysis criteria. Journal of Modern Applied Statistical Methods, 5(2), 344-346.

Zimmerman, M. (2012). Is there adequate empirical justification for radically revising the personality disorders section for DSM-5? Personality Disorders: Theory, Research, and Treatment, 3(4), 444-457. doi:10.1037/a0022108

Lucas de Francisco Carvalho is a Professor of the Universidade São Francisco.

Giselle Pianowski is a Ph.D. candidate of the Graduate Program in Psychology of the Universidade São Francisco.

Received: June 19, 2014

1st Revision: Oct. 28, 2014

2nd Revision: Dec. 3, 2014

Approved: Dec. 11, 2014

How to cite this article:

Carvalho, L. F., \& Pianowski, G. (2015). Revision of the dependency dimension of the Dimensional Clinical Personality Inventory. Paidéia (Ribeirão Preto), 25(60), 57-65. doi: 10.1590/1982-43272560201508 